\title{
Estudo da mata ciliar do rio Piranhas na sub-bacia do médio Piranhas paraibano
}

As matas ciliares compreendem a cobertura vegetal nativa, ou seja, o sistema florestal comumente situado em faixas de margens de rios ou outros corpos de água, em torno de nascentes, lagos, represas artificiais ou naturais. Assim, como base nesse contexto, o objetivo deste estudo foi analisar a situação ambiental da mata ciliar do rio Piranhas, por meio do uso de Sistema de Informações Geográficas (SIG's), bem como indicar medidas de Educação Ambiental. O método utilizado foi o estudo de caso, com utilização de pesquisa exploratória, e consistiu na delimitação das Áreas de Preservação Permanente (APP's) do rio Piranhas e de mapas de uso e ocupação do solo, no levantamento de dados de profundidade do rio, buscando analisar a superfície do fundo do rio e assim identificar possível assoreamento do seu leito, por fim foi indicado medidas de educação ambiental baseadas no diagnóstico da análise da mata ciliar.Com superficie do fundo do rio e assim identificar possivel assoreamento do seu leito, por fim foi indicado medidas de educação ambiental baseadas no diagnóstico da análise da mata ciliar.Com encontra-se exploradas por atividades agrícolas e cerca de $63,1 \%$ encontra-se com solo exposto. Assim, conclui-se que a supressão da vegetação nas APPs do rio Piranhas pode esta acelerando o processo de assoreamento do rio, podendo causar outros impactos ambientais à exemplo da contaminação das águas superficiais e, consequentemente, subterrâneas. Portanto, para que seja possivel mudar o cenário diagnosticado nas APPs do rio Piranhas, são necessárias a adoção de medidas de educação e conscientização ambiental aos proprietários rurais e populações ribeirinhas.

Palavras-chave: Supressão vegetal; Assoreamento; Matas ciliares; Educação Ambiental.

\section{Study of the riparian forest of the Piranhas River in the middle Piranhas sub-basin of Paraiba}

\begin{abstract}
The riparian forests comprise native vegetation cover, that is, the forest system commonly situated along riverbanks or other bodies of water, around springs, lakes, artificial or natural dams. Thus, as a base in this context, the objective of this study was to analyze the environmental situation of the Piranhas river ciliary forest, through the use of Geographic Information System (GIS), as well as to indicate Environmental Education measures. The method used was the case study, with the use of exploratory research, and consisted in the delimitation of the Permanent Preservation Areas (APPS) of the Piranhas River and maps of land use and occupation, in the survey of river depth data, searching to analyze the surface of the river bottom and thus identify possible silting of its bed, finally it was indicated measures of environmental education based on the diagnosis of the analysis of the ciliary forest. Based on this, it was verified that the PPAs are not being preserved, once that of the total area covered by them, only $35.9 \%$ is protected with native vegetation, $1.2 \%$ are exploited by agricultural activities and about $63.1 \%$ are with exposed soil. Thus, it is concluded that the suppression of vegetation in the Piranhas River PPAs is accelerating the process of sedimentation of the river and may cause other environmental impacts, such as the contamination of surface waters and, consequently, underground. Therefore, in order to change the diagnosed scenario in the PPAs of the Piranhas river, it is necessary to adopt measures of education and environmental awareness to the rural owners and riverine populations.
\end{abstract}

Keywords: Vegetal suppression; Sedimentation; Riparian forests; Environmental education

Topic: Engenharia Ambiental

Reviewed anonymously in the process of blind peer
Received: 09/12/2019

Approved: 17/01/2020
Katia Barbosa da Silva

Instituto Federal do Rio Grande do Norte, Brasil http://lattes.cnpq.br/6338865657491678

katiabarbosas@hotmail.com

Rômulo Wilker Neri de Andrade (iD

Instituto Federal do Rio Grande do Norte, Brasil http://lattes.cnpq.br/5753728802510908 http://orcid.org/0000-0002-0561-7507 romulo_wilker@hotmail.com

\section{Luara Lourenço Ismael (iD)}

Universidade Federal de Campina Grande, Brasil http://lattes.cnpq.br/6306718104224910 http://orcid.org/0000-0002-8773-8256 luara ismael@hotmail.com
Andressa Noronha Barbosa da Silva (iD) Instituto Federal do Rio Grande do Norte, Brasil http://lattes.cnpq.br/2721128645663357 http://orcid.org/0000-0002-6584-5771 noronha.andressa@gmail.com

Narla Sathler de Oliveira Musse (ic) Instituto Federal do Rio Grande do Norte, Brasil http://lattes.cnpq.br/2477295938118466 http://orcid.org/0000-0002-6894-2884 narla.musse@ifrn.edu.br

Adriana Maria dos Santos (iD

Universidade Federal de Campina Grande, Brasil http://lattes.cnpq.br/0525608868446929 http://orcid.org/0000-0002-5070-6111 ttstadriana@gmail.com lury Araujo Macêdo Dantas (iD Universidade Federal de Campina Grande, Brasi http://lattes.cnpq.br/4702438880544717 http://orcid.org/0000-0002-7193-8560 iury.araujo@hotmail.com

\section{Gabriela Braga de Sá id}

Universidade Federal de Campina Grande, Brasil http://lattes.cnpq.br/0287804224111392 gabrielasa.1@hotmail.com

\section{Maíla Vieira Dantas}

Universidade Federal de Campina Grande, Brasi http://lattes.cnpq.br/1264469851207038 http://orcid.org/0000-0001-7751-0533 maila.vieira02@gmail.com d

DOI: 10.6008/CBPC2179-6858.2020.001.0020
Referencing this:

SILVA, K. B.; ANDRADE, R. W. N.; ISMAEL, L. L.; SILVA, A. N. B.; MUSSE, N. S. O.; SANTOS, A. M.; DANTAS, I. A. M.; SÁ, G. B.; DANTAS, M. V.. Estudo da mata ciliar do rio Piranhas na sub-bacia do médio Piranhas paraibano. Revista Ibero Americana de Ciências Ambientais, v.11, n.1, p.211-221, 2020. DOI: http://doi.org/10.6008/CBPC2179$\underline{6858.2020 .001 .0020}$ 


\section{INTRODUÇÃO}

As matas ciliares são de fundamental importância para a manutenção e qualidade dos recursos hídricos, bem como para a fixação de sedimentos, evitando o assoreamento nas margens dos rios. Além disso, atuam como abrigo e fonte de alimentação para a fauna terrestre e aquática (CARMO et al., 2016). 0 processo histórico de ocupação, desenvolvimento e crescimento urbano ocorreu em torno dos rios, ocasionando diversos impactos ambientais resultantes da ação antrópica, com influência direta nos corpos hídricos (CARMO et al., 2016). Como forma de mitigar esses impactos foram instituídas por lei, as Áreas de Preservação Permanente (APP's) (MESQUITA et al., 2011). Definidas pela Lei $n^{\circ} 12.651 / 2012$ como áreas cobertas ou não por vegetação nativa, que possui a função de proteger os recursos naturais ambientais, os recursos hídricos, a paisagem, a estabilidade geológica, a fauna e flora e assegurar o bem-estar da sociedade (BRASIL, 2012).

Devido à grande importância ecológica e ambiental dessas áreas, tem-se a necessidade de fiscalizar e monitorar a existência, eficácia e eficiência da preservação desses ecossistemas e, para isso, a utilização de Sistema de Informações Geográficas (SIG's) surgem como grandes auxiliadores nessas atividades, uma vez que permitem uma análise rápida, menos onerosa e confiável por meio de técnicas especializadas e simples (FOCHI et al., 2015).

Além da aplicação das ferramentas de SIG's, é fundamental a sensibilização ambiental da população quanto a preservação dos corpos de água, dos solos e da biodiversidade. Assim, programas de recuperação e restabelecimento das matas ciliares são fundamentais para os proprietários rurais, que deverão ser reconhecidos como produtores e conservadores dos recursos hídricos, os quais são servidos, na maioria dos casos, as populações urbanas, que também devem ser sensibilizados (REIS et al., 2006).

O rio Piranhas, no estado da Paraíba, é responsável pelo abastecimento de vários núcleos urbanos, sendo utilizado como fonte de recurso para a população ribeirinha, tanto para o consumo doméstico quanto para a irrigação de áreas agrícolas. É notável que boa parte da mata ciliar desse corpo hídrico tem sido explorada pelos proprietários de forma irregular. Assim, este estudo tem como objetivo analisar a situação ambiental da mata ciliar do rio Piranhas, através do uso de SIG's, bem como indicar medidas de Educação Ambiental.

\section{MATERIAIS E MÉTODOS}

O método utilizado foi o estudo de caso, com utilização de pesquisa de natureza exploratória, tendo como objetivo a situação ambiental da mata ciliar do rio Piranhas no estado da Paraíba, buscando identificar o atendimento às APPs e a situação do assoreamento do rio e, por fim, indicou-se medidas de educação e conscientização ambiental.

\section{Caracterização da Área de Estudo}

O rio Piranhas, com coordenadas geográficas $6^{\circ} 43^{\prime} 54.07^{\prime \prime S}$ e $37^{\circ} 48^{\prime} 8.92^{\prime \prime O}$ no município de Pombal- 
PB e $6^{\circ} 26^{\prime} 8.79^{\prime \prime S}$ e $37^{\circ} 22^{\prime} 53.57^{\prime \prime O}$ na divisa da Paraíba com o Rio Grande do Norte, está inserido na bacia hidrográfica Piancó-Piranhas-Açu, mais especificamente na Unidade de Planejamento Hidrológico (UPH) do Médio Piranhas Paraibano, localizada no oeste do estado da Paraíba (PB) (ANA, 2016). Na Figura 1, pode-se visualizar o mapa de localização da área de estudo.

O rio Piranhas corta 4 municípios no estado da Paraíba (Figura 2), que juntos possuem uma população de 87.392 habitantes, conforme estimativa populacional do IBGE para 2018, sendo que o município de São Bento possui 33.796 habitantes, o município de Pombal possui 32.749 habitantes, já o município de Paulista, tem 12.260 habitantes, e o de Riacho dos Cavalos, 8.587 habitantes.

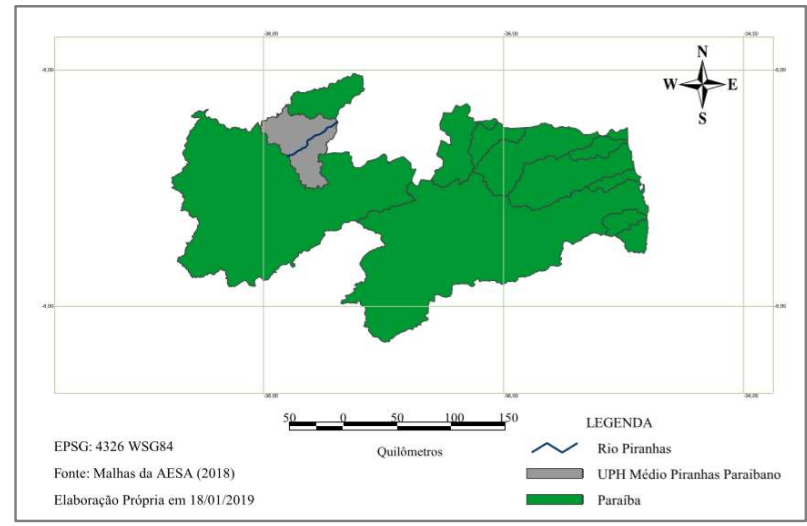

Figura 1: Mapa de localização da área de estudo.

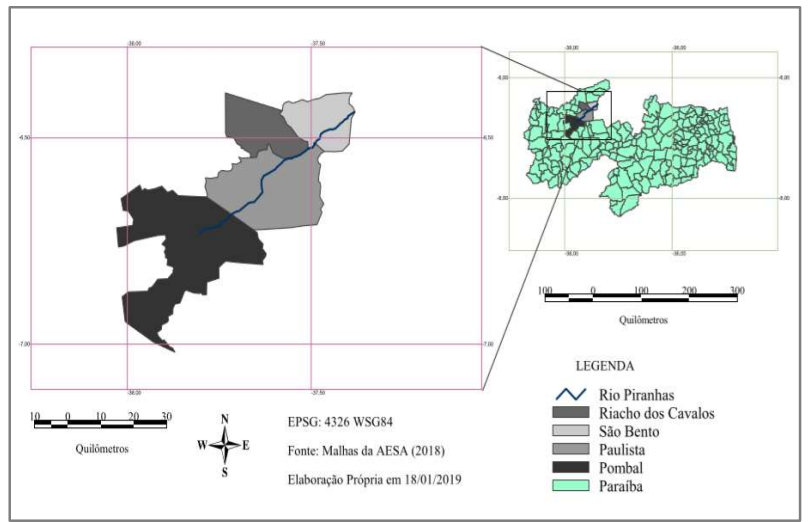

Figura 2: Municípios cortados pelo rio Piranhas.

De acordo com o resumo executivo do Plano de Recursos Hídricos da Bacia Piancó-Piranhas-Açu (ANA, 2016), os principais usos da bacia são agricultura irrigada, pecuária, aquicultura, indústria, abastecimento humano e abastecimento rural. As principais características físico-bióticas da UPH Médio Piranhas Paraibano incluem o tipo climático B (clima árido), segundo a classificação de Köppen. Nessa área, a precipitação média é de $908 \mathrm{~mm} /$ ano e taxa de evaporação média de $2.937 \mathrm{~mm} /$ ano (ANA, 2016). A temperatura média varia entre $24,2^{\circ} \mathrm{C}$ e $28,2^{\circ} \mathrm{C}$, segundo as Normais Climatológicas do Instituto Nacional de Meteorologia (INMET).

O rio Piranhas apresenta uma vegetação ciliar arbórea-arbustiva aberta, inserida no bioma Caatinga, assentada sobre Luvissolos e Neossolos Flúvicos, com fisionomia bastante perturbada pela ação antrópica (SILVA et al., 2016). Por fim, o bioma predominantemente na UPH Médio Piranhas Paraibano é a Caatinga. A UPH Médio Piranhas Paraibano abrange 24 municípios e tem o rio em estudo como a principal fonte hídrica. Ele nasce a partir da confluência do rio Piancó com o rio do Peixe no município de Pombal e segue em direção ao estado do Rio Grande do Norte. Os principais reservatórios que compõem apenas a UPH Médio Piranhas Paraibano são o açude do Carneiro, o açude Engenheiro Arcoverde e açude Riacho dos Cavalos, todos com acúmulo superior a $10 \mathrm{hm}^{3}$ e considerados reservatórios estratégicos, conforme Tabela 1 (ANA, 2016).

\section{Delimitação das Áreas de Preservação Permanente - APPs}

Para análise das APPs foi realizado um levantamento da largura média da calha do leite regular do rio por meio de imagens de satélite do software Google Earth Pro de novembro de 2016. A medição foi realizada a cada $1 \mathrm{~km}$, sendo quantificados 62 pontos, visto que o trecho do rio em estudo possui $62 \mathrm{~km}$. 
Com o auxílio da ferramenta buffer do software gvSIG versão 2.4.0.2850 e a definição das faixas marginais definidas do NCF, determinou-se os limites das APPs do rio Piranhas na Paraíba.

Posteriormente foi criado um mapa de uso e ocupação do solo com o uso de imagem de satélite do software Google Earth Pro para identificar as áreas que atendem as especificações do Novo Código Florestal. Em seguida, realizou-se uma sobreposição do mapa de uso e ocupação do solo com o mapa das APPs. Após a sobreposição desses mapas, as áreas que atendem as APPs de acordo com o NCF foram devidamente quantificadas, executando as funções de cálculo de área, pelas ferramentas do gvSIG. Os arquivos criados no software Google Earth Pro foram salvos no formato kml e convertidos por meio do software GPS TrackMaker Pro versão 4.9 para o formato shapefile.

\section{Análise da Existência de Assoreamento do Leito do Rio Piranhas}

A análise do assoreamento do rio foi realizada por meio de dados gerados no medidor de vazão Flowtracker, cedido por uma empresa que realiza medições de vazões nos rios principais da Bacia PiranhasAçu. O Flowtracker gera dados de vazão, assim como possibilita a medição de vários parâmetros na seção em medição, tais como profundidade, velocidade e ruído da água.

Para análise do assoreamento do rio nesses pontos foram utilizados os dados de profundidade dos últimos 18 meses dos quatro pontos de medição vazão do rio Piranhas no estado da Paraíba, sendo três estações hidrometeorológicas (Vassouras, Curralinho e Divisa) e a montante da captação de água da Companhia de Água e Esgotos da Paraíba (CAGEPA) em São Bento/PB. Por meio desses dados foi possível analisar as variações da superfície do fundo do rio e possível assoreamento da calha fluvial. A tabulação desses dados foi realizada por meio do software Excel, versão 2016, onde foi possível elaborar gráficos que auxiliaram na compreensão dos resultados.

\section{Propostas de Educação Ambiental}

As medidas de educação ambiental foram direcionadas aos proprietários rurais e aos moradores da região em estudo. Tais medidas foram baseadas na descrição da tabulação dos dados e na literatura pertinente, bem como no que destaca as normas e leis de educação ambiental.

\section{RESULTADOS E DISCUSSÃO}

Foi identificado que a largura média do rio Piranhas é de 52,1 m, com trechos de maior e menor largura localizados no município de Paulista/PB, medindo cerca de $11 \mathrm{~m}$ e $261 \mathrm{~m}$, respectivamente. Contudo, em média, a APP que deve ser adotada nas margens do rio em estudo, de acordo com o NCF, Lei $n^{\circ}$ 12.651/2012, é de $100 \mathrm{~m}$, tendo em vista que ele determina $100 \mathrm{~m}$ para os cursos d'água que tenham de 50 a 200 m largura. Por meio da Figura 3 é possível observar a delimitação das APPs ao longo do rio Piranhas.

O rio Piranhas no estado da Paraíba possui extensão de 62,13 m de comprimento e uma área de cerca de $6.426 .610 \mathrm{~m}^{2}$. Já área da APP média é de $12.843 .143 \mathrm{~m}^{2}$, que corresponde a $100 \mathrm{~m}$ de faixas marginais (margem direita e margem esquerda). Desse total de área, apenas 35,9\% se encontra protegida, 
ou seja, coberta com vegetação nativa ou não, 1,2\% se encontra exploradas por atividades agrícolas e cerca de $63,1 \%$ se encontra com solo exposto. Nas Figuras 4, 5 e 6 é possível visualizar os mapas de uso e ocupação do solo das APPs em cada município onde passa o rio em estudo.

De acordo com levantamento ambiental realizado em 2007 no rio Piranhas-Açu, as atividades agrícolas e a pecuária realizadas nas margens desses rios tem contribuído para a degradação de grandes extensões de mata ciliar, somado a atividade de extrativismo da lenha para a indústria cerâmica (PARAíBA et al., 2007).

No município de Pombal/PB, o rio Piranhas tem uma extensão de 11,74 m, representando $18,89 \%$ de toda extensão do rio. Nesse trecho, a APP se encontra com $47,0 \%$ de sua área preservada, cerca de $2,79 \%$ está sendo utilizada para atividades agrícolas e 50,21\% encontra-se com solo exposto. Tais características podem ser percebidas por meio da Figura 4.

De acordo com os dados levantados e com base na Figura 4, cerca da metade da APP encontra-se com exposição do solo, o que pode ocasionar aumento da erosão e consequentemente da descarga sólida, alterando o escoamento da água no rio. Segundo Calijuri et al. (2013), cada curso de água tem uma capacidade limite de transporte de sedimentos, assim sendo, conforme os atributos citados, é possível que ocorra aumento da disposição de sedimentos, ou seja, assoreamento do leito do rio.

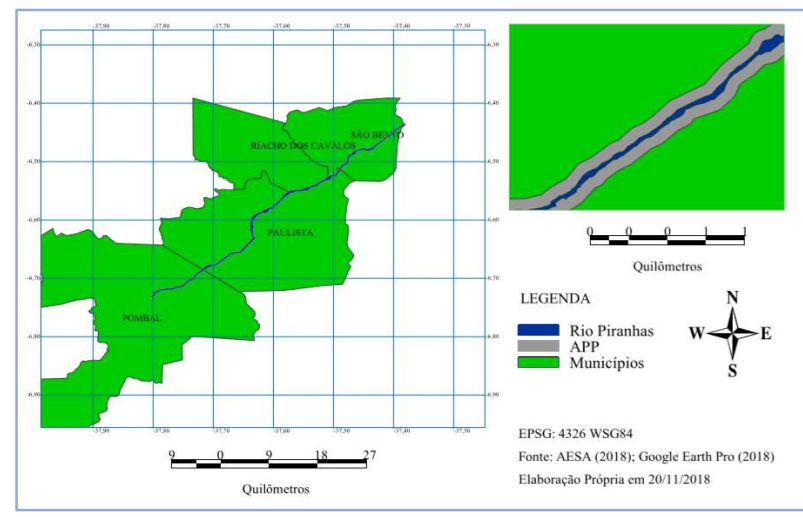

Figura 3: Área de APP do Rio Piranhas na Paraíba.

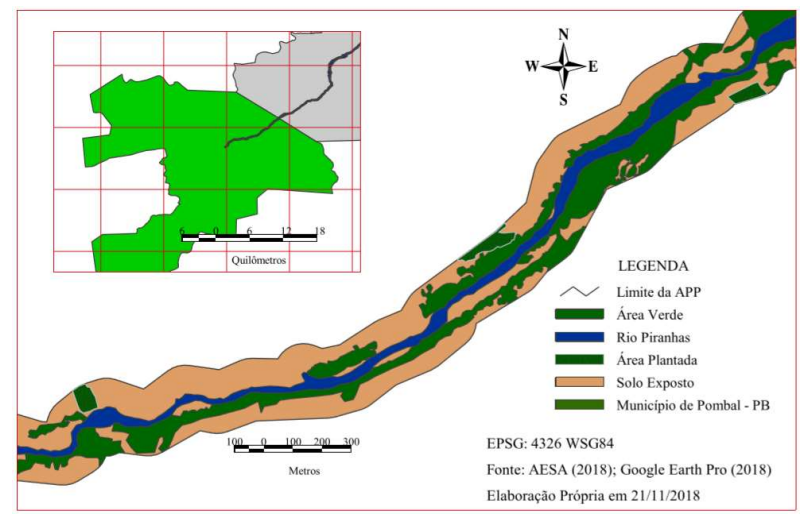

Figura 4: Áreas de APP do rio Piranhas no município de Pombal/PB.

No município de Paulista/PB, o rio Piranhas possui uma extensão de 34,57 m, representando 55,64\% de toda extensão do rio. A área preservada da APP nesse município é de apenas $37,76 \%$, onde $61,32 \%$ do solo está totalmente exposto e cerca de $0,92 \%$ é utilizado para atividades agrícolas, conforme pode ser percebido na Figura 5. É sabido que o município de Paulista produz grandes quantidades de queijos, sendo, portanto, produtor de leite e possuindo um considerável rebanho bovino, que pode estar associado a supressão da vegetação nas APPs. Além disso, diversas outras atividades são exercidas no município, como extração de madeira, agricultura, dentre outras.

Já no município de São Bento/PB, o rio Piranhas tem 15,82 m de extensão, representando $25,46 \%$ de todo o rio em estudo. A área conservada da APP nesse município é $31,80 \%$, cerca de $1,28 \%$ é destina a produção agrícola e $0,06 \%$ a instalação de viveiros para criação de peixes, portanto cerca de $66,86 \%$ de toda APP estar desprotegida, ou seja, encontra-se com o solo exposto. Na Figura 6 é possível observar um trecho 
do rio e do uso e ocupação do solo na APP.

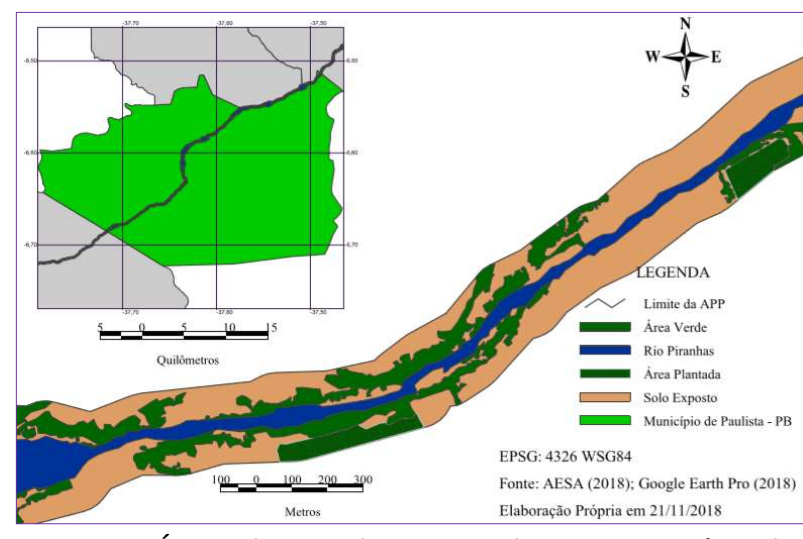

Figura 5: Áreas de APP do rio Piranhas no município de Paulista/PB.

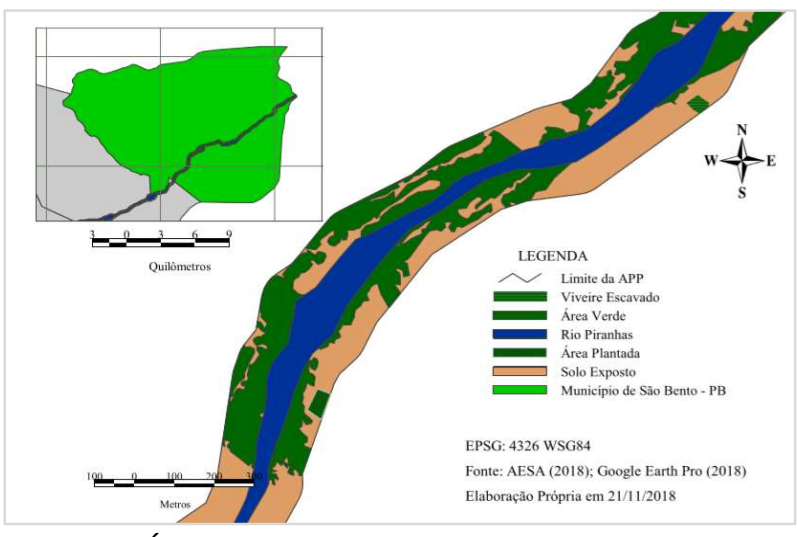

Figura 6: Áreas de APP do rio Piranhas no município de São Bento/PB.

Na Figura 6, percebe-se que a margem direita do rio Piranhas no município de São Bento apresenta menor cobertura vegetal, assim como em toda extensão do rio. Foi diagnosticado que a maior cobertura vegetal é na APP da margem esquerda do rio com cerca de 51,64\%, enquanto a margem direita possui cerca de $48,36 \%$.

Silva et al. (2016), em estudo realizado no município de São Bento, destacaram que a cobertura vegetal da margem do rio Piranhas é de 5 a 20 m de largura. No entanto, esse estudo constatou que existem alguns trechos marginais em que toda a APP está protegida (da calha do rio até o limite da APP) e outros, que não existem nenhum tipo de cobertura vegetal, conforme mostra a Figura 6. Percebe-se que o município com maior extensão de rio é o de Paulista, seguido de São Bento e Pombal. Todavia, o município que apresentou maior conservação de suas matas ciliares referentes ao rio Piranhas foi Pombal (47,0\%), seguido por Paulista $(37,76 \%)$ e São Bento $(31,80)$.

A principal justificativa para a maior exploração das matas ciliares das margens do rio Piranhas em Paulista e São Bento, relacionam-se com a inexistência de políticas de educação ambiental voltadas para conservação da natureza, e, possivelmente, por este rio ser a principal fonte hídrica de tais municípios, e, suas áreas adjacentes serem mais exploradas pelos proprietários rurais. Já em Pombal, a principal fonte hídrica é o rio Piancó, que corta boa parte de tal município, e portanto, as águas do rio Piranhas são menos utilizadas nas atividades que costumeiramente ocorrem nas faixas marginais. Nas Figuras 7a, 7b, 7c e 7d, pode-se observar imagens das margens do rio Piranhas nos municípios de Paulista (Figuras 7a e 7b) e São Bento (Figuras 7c e 7d).

De acordo com Rodrigues et al. (2008), as matas ciliares de um corpo hídrico contribuem para o abastecimento do lençol freático, oferecem proteção contra a erosão do solo, evitando o assoreamento dos mananciais, além de reduzir impactos sobre a biota aquática. Estão intimamente relacionadas à qualidade da água para consumo humano e animal, atuam como filtros, retendo resíduos de agrotóxicos e sedimentos, dentre outros benefícios.

Contudo, para analisar se o corpo hídrico em estudo se encontra com problemas de assoreamento devido a supressão da vegetação em suas margens, verificou-se dados de profundidade em quatro secções 
transversais do leito do rio Piranhas, onde foi possível analisar se a superfície do fundo do leito do rio sofreu variações ao longo dos anos de 2017 e 2018 , conforme se segue.
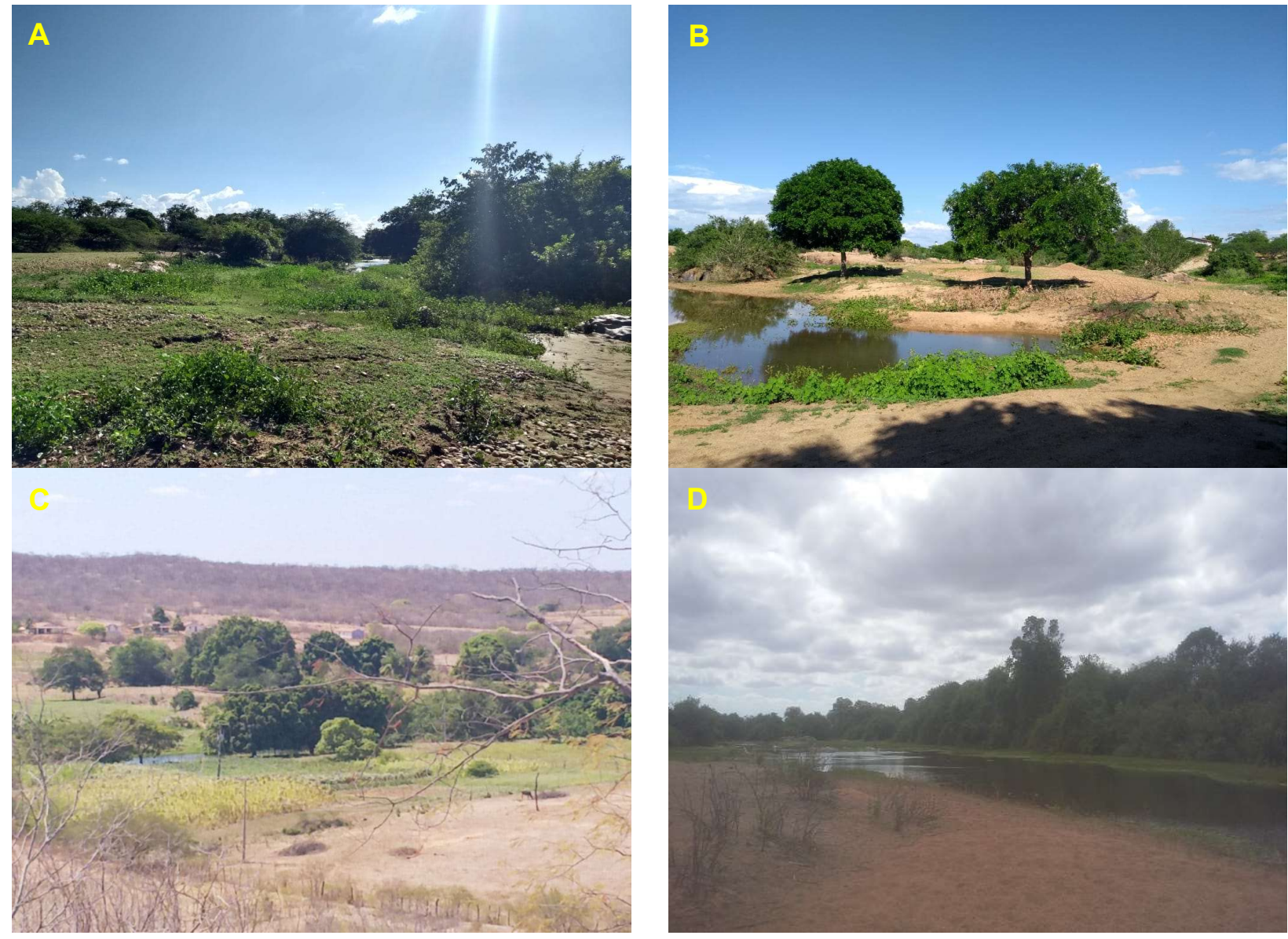

Figura 7: Imagens das margens do rio Piranhas.

Nos gráficos de 1 a 7, pode-se visualizar dados da superfície do fundo do rio Piranhas nas estações hidrometereológicas Vassouras, no município de Pombal, Curralinho, no município de Paulista e Divisa, na divisa do Rio Grande do Norte com a Paraíba, além do ponto de medição de vazão a montante da captação de água da CAGEPA em São Bento.

Para medição da secção transversal do rio nos pontos de análise, adotou-se uma média entre as larguras do rio nos meses analisados. Observa-se, por meio dos Gráficos 1 e 2, que a largura média da Estação Vassouras nos anos de 2017 e 2018 foi 41 m. Nota-se ainda que ocorreu uma certa variação na superfície do fundo do rio durante os meses analisados no ano de 2017, com maior diferenciação no mês de setembro, que apresentou pouca modificação na superfície ao longo da secção transversal do rio.

Quanto ao ano de 2018, foram utilizados dados de dois meses para analisar a situação da superfície no fundo do rio e, constatou-se grande variação quando comparado ao ano de 2017. Isso pode ter ocorrido devido as chuvas do início do ano, que provavelmente carreou sedimentos, provocando alterações no fundo do rio. Tais sedimentos podem ter origem na supressão da mata ciliar ou da cobertura vegetal, que segundo Calijuri et al. (2013), pode resultar em um aumento da erosão e consequente acréscimo da descarga sólida.

De acordo com levantamento ambiental realizado em 2007 no rio Piranhas-Açu, as atividades agrícolas e a pecuária contribuem para a degradação de grandes extensões de mata ciliar, o que resulta em 
erosão dos solos e consequente assoreamento do corpo hídrico. Destaca-se, ainda, que o aporte de sedimentos para o leito do rio recebe contribuições da ação humana por meio de atividades de exploração de areia para a indústria da construção civil, o que contribui para alterações do traçado do leito do rio (PARAÍBA et al., 2007).

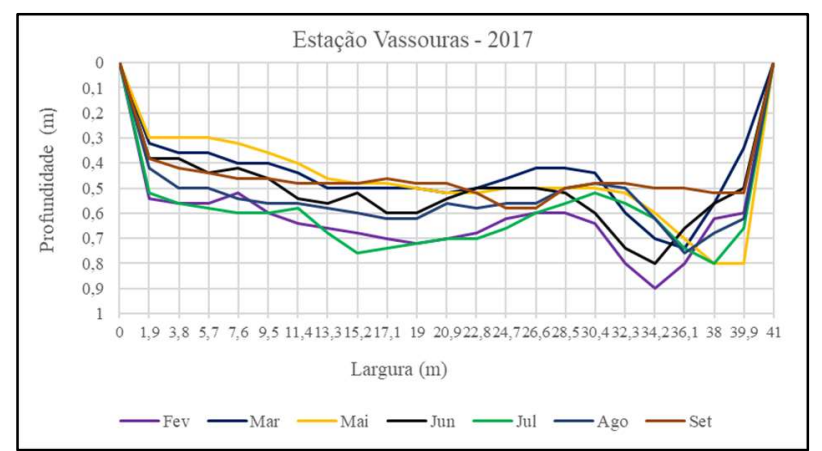

Gráfico 1: Superfície do fundo do rio Piranhas na Estação Vassouras em 2017.

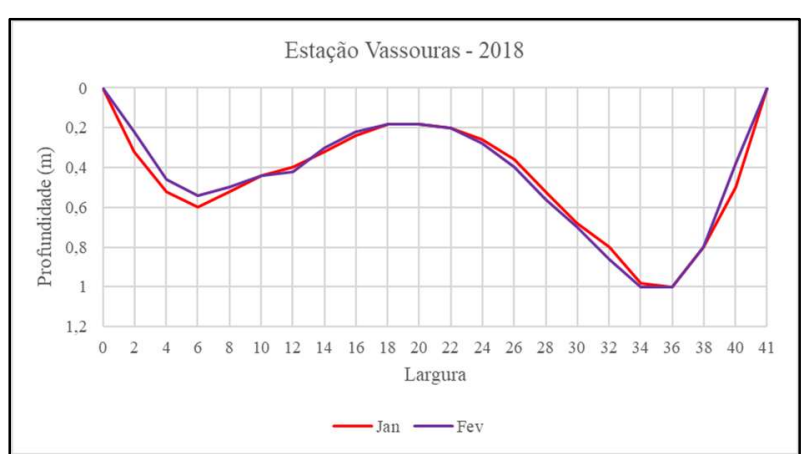

Gráfico 2: Superfície do fundo do rio Piranhas na Estação Vassouras em 2018.

Quanto ao acúmulo e/ou modificação do fundo do rio por sedimentos na estação Curralinho no ano de 2017, percebeu-se variações conforme o Gráfico 3, com maior amplitude no mês de março, onde a profundidade variou bastante entre uma margem e outra, o que não ocorreu com tanta intensidade nos demais meses. Já o mês que sofreu menos variação foi setembro, diferindo também dos demais meses.

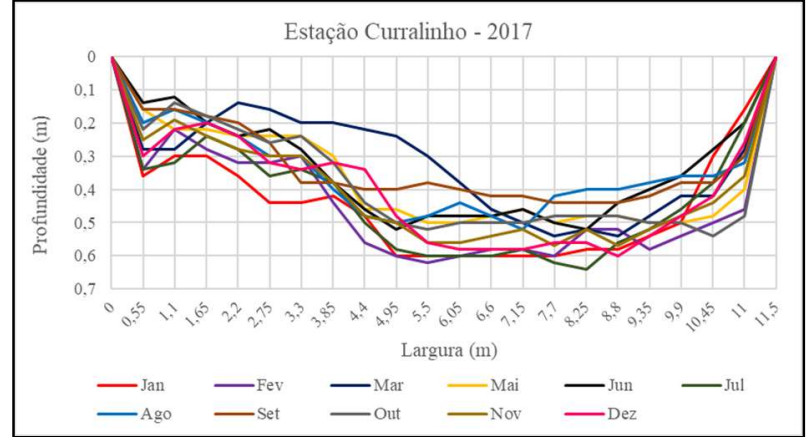

Gráfico 3: Superfície do fundo do rio Piranhas na Estação Curralinho em 2017.

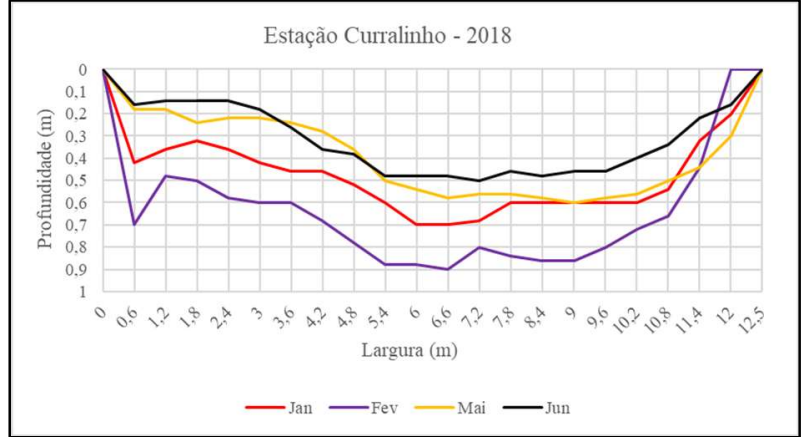

Gráfico 4: Superfície do fundo do rio Piranhas na Estação Curralinho em 2018.

Quanto ao ano de 2018, percebeu-se que o fundo do rio, nos meses de janeiro e fevereiro, apresentou superfícies diferentes quando comparado aos demais meses (Gráfico 4), possivelmente por ter sido os meses que mais ocorreram precipitações segundo dados da Agência das Águas do Estado da Paraíba - AESA (2018), o que pode ter provocado o carreamento de sedimentos no leito do rio. Contudo, em todos os meses ocorreram variações na superfície do fundo do rio, que pode ter sido influenciada pelo escoamento natural, uma vez que os rios são elementos que naturalmente move o solo na forma de sedimentos. Tais diferenciações também podem ter sofrido influência da erosão dos solos das proximidades do rio, ocasionadas pela supressão vegetal nas margens no município de Paulista, tendo em vista que apenas 37,76\% das APP são preservadas nesse município.

Em relação a superfície do fundo do rio, a montante da captação de água da CAGEPA em São Bento, percebe-se, por meio dos Gráficos 5 e 6, que também ocorreram certas variações quando comparou-se os 
meses analisados durante os anos de 2017 e 2018. Tais variações ocorreram com maior intensidade nos meses em que o rio se encontrava com maior volume de água, a exemplo dos meses de novembro de 2017 e fevereiro de 2018. Percebe-se ainda que de todos os pontos já analisados nesse ponto (captação São Bento), o rio é o mais raso que nos demais, chegando a atingir uma profundidade máxima de 0,52 $\mathrm{m}$.

Calijuri et al. (2013), afirmam que quando ocorre um aumento na vazão líquida em um rio, ocorre também a erosão do leito e margens, e quando ocorre a diminuição da descarga líquida, tende a ocorrer deposição de sentimentos. Essas características podem ter provocado tais variações no fundo do rio Piranhas no ponto analisado.

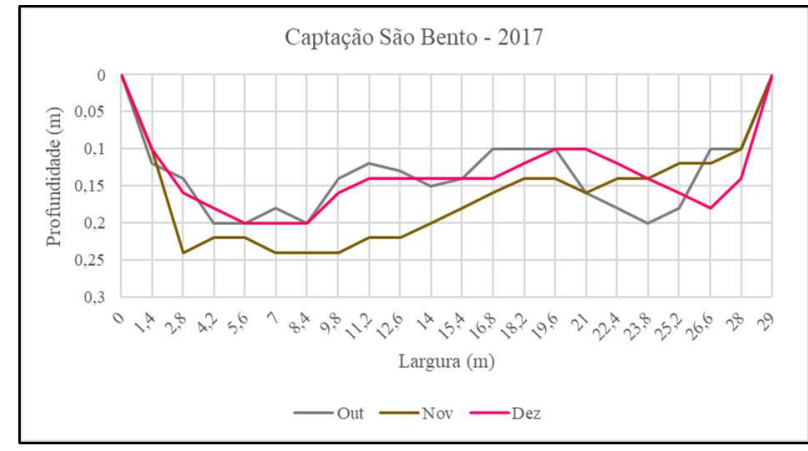

Gráfico 5: Superfície do fundo do rio Piranhas na Captação em São Bento em 2017.

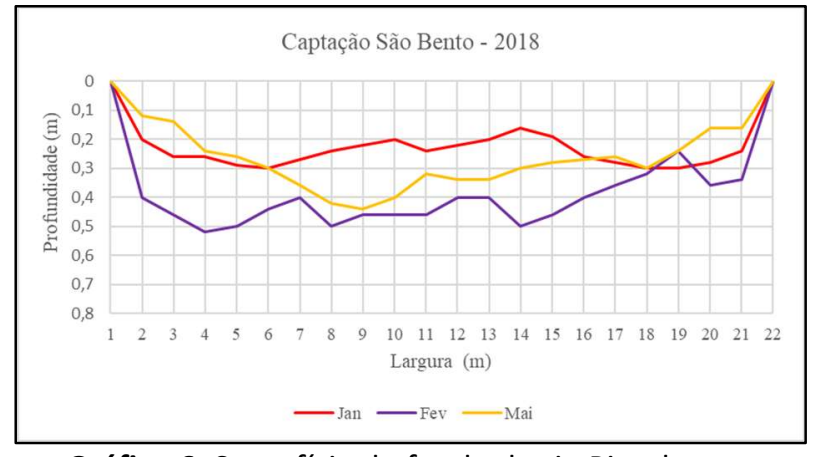

Gráfico 6: Superfície do fundo do rio Piranhas na Captação São Bento em 2018.

De todos as estações analisadas, quanto ao possível assoreamento do leito do rio Piranhas, na estação Divisa, na divisa da Paraíba com o Rio Grande do Norte, ocorreram um menor número de medições de vazões, uma vez que nem sempre o leito do rio, nesse trecho, é perenizado, tendo em vista a situação hídrica da região. Conforme Gráfico 7, percebe-se que o fundo do rio também sofre variações quando se compara os meses analisados. Tais características não diferem dos demais pontos de medição já mencionados e, provavelmente, tais varrições são ocasionadas pelos mesmos fatores destacados anteriormente.

Diante dos possíveis impactos que os problemas destacados podem causar ao rio em estudo, ao solo, aos ecossistemas aquáticos, a flora e a fauna, bem como as populações ribeirinhas e aquelas pessoas que de alguma forma utilizam a água proveniente do rio, nota-se a importância de indicar medidas de educação ambiental para os proprietários rurais e moradores dos municípios em estudo especialmente aqueles que habitam nas proximidades do rio Piranhas.

Assim, indica-se que sejam adotados programas de recuperação das matas ciliares, com vista para o reflorestamento das áreas desmatadas, conforme determina a Lei $\mathrm{n}^{\circ}$ 12.651/2012, para os proprietários rurais de cada município cortado pelo rio Piranhas. Além disso, indica-se que sejam adotadas palestras sobre APP e EA nas associações de agricultores, bem como nas escolas das comunidades rurais e urbanas para que as crianças passem as informações para os familiares, e que no futuro sejam cidadãs conscientes dos impactos que a supressão vegetal pode causar a um curso de água, ao próprio solo, bem como aos seres vivos em geral. Outra medida de EA é a aplicação de cursos de boas práticas de conservação/recuperação do solo e da água para os proprietários rurais, com o objetivo de preservar as áreas verdes e recuperar os solos 
expostos.

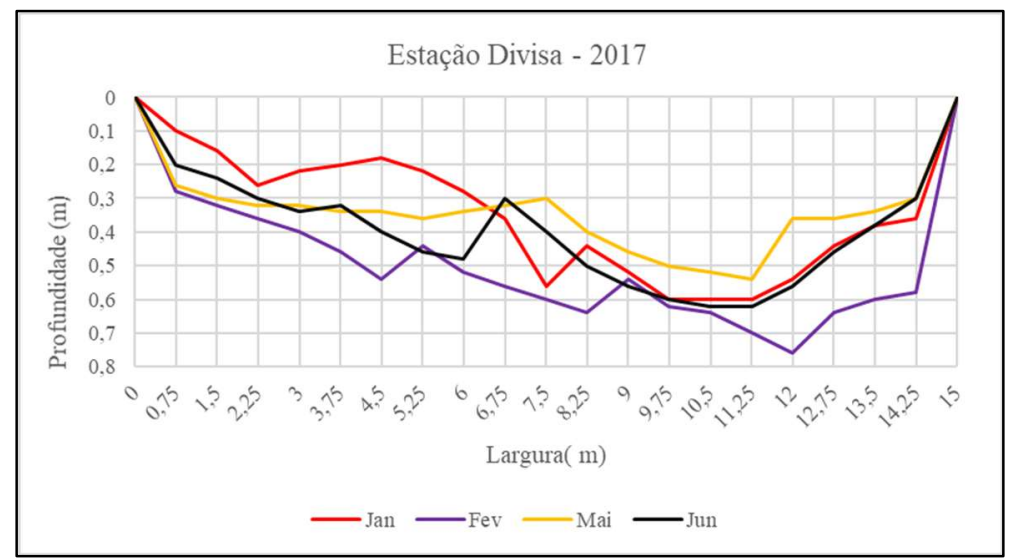

Gráfico 7: Superfície do fundo do rio Piranhas na Estação Divisa em 2017.

De acordo com Nascimento et al. (2013), ações de educação ambiental voltadas à conservação da natureza devem promover diálogos e trocas de saberes entre os diferentes atores sociais visando à produção de propostas de planejamento ambiental participativo e a mudanças de hábitos e valores, podendo gerar uma diminuição dos impactos ambientais. Sendo assim, as ações educacionais atuam como importantes instrumentos na promoção da conservação do meio ambiente, uma vez que promovem sensibilização sobre a necessidade de conservação.

\section{CONCLUSÕES}

Percebeu-se que apenas uma pequena parcela das APPs do rio Piranhas é protegida, e consequentemente, existem grandes extensões de solo exposto, e áreas cultivadas. Constatou-se, ainda, que o município que mais preserva as APPs do rio é Pombal, já o que menos preserva é o município de São Bento. Quanto a superfície do fundo rio, diagnosticou-se que todos os pontos analisados sofrem variações na sua superfície, especialmente em épocas de cheias e que provavelmente essa variação é alterada pelo transporte de sedimentos provenientes da erosão do solo devido a supressão da vegetação nas margens do rio.

Assim, conclui-se que a supressão da vegetação nas APPs do rio Piranhas pode estar acelerando o processo de assoreamento do rio, podendo causar outros impactos ambientais à exemplo da contaminação das águas superficiais e, consequentemente, subterrâneas. Portanto, para que seja possível mudar o cenário diagnosticado nas APPs do rio Piranhas, é necessária a adoção de medidas de educação e conscientização ambiental aos proprietários rurais e populações ribeirinhas.

\section{REFERÊNCIAS}

AESA. Precipitação máxima dos municípios: meteorologiachuvas. Paraíba: AESA, 2018.

\section{ANA. Plano de recursos hídricos da bacia hidrográfica do rio Piancó-Piranhas-Açu. Brasília: ANA, 2016.}

BRASIL. Lei n.12651 de $\mathbf{2 5}$ de maio de 2012. Dispõe sobre a proteção da vegetação nativa. Brasília: DOU, 2012.

CALIJURI, M. C.; CUNHA, D. G. F.. Engenharia Ambiental: conceitos, tecnologia e gestão. 5 ed. Rio de Janeiro: Elsevier,
2013.

CARMO, S. E.; BONETTO, N. C. F.. Implantação de Matas Ciliares para Recuperação e Reabilitação de Recursos Hídricos. Revista Acadêmica Oswaldo Cruz, São Paulo, v.3, n.9, 2016.

FOCHI, D. A. T.; CORAZZA, R.; MESACASA, L.; MELO, N. G. Utilização de ferramentas de geoprocessamento para a delimitação das Áreas de Preservação Permanente (APPs) no município de Passo Fundo, segundo o Novo Código Florestal 
(Lei 12.651-2012). In: CONGRESSO BRASILEIRO DE GESTÃO AMBIENTAL, 6. Anais. Porto Alegre: IBEAS, 2015.

MESQUITA, R. A. S.; BRITO, M. R.; MARINHO, A. A.; MURAISHI, C. T.. A Importância das Áreas de Preservação Permanente (APP's). Palmas, 2011.

NASCIMENTO, M. V. E.; ALMEIDA, E. A.. Efetivação e Análise de Ações Educativas Promotoras da Biodiversidade em uma Área de Proteção Ambiental Costeira do Nordeste/Brasil. Natal: UFRN, 2013.

PARAÍBA; RIO GRANDE DO NORTE. Levantamento Ambiental do Rio Piranhas-Açu: Atividades Poluidoras ou Potencialmente Poluidoras. Natal: Instituto de Gestão das
Água do RN; Natal: Instituto de Defesa do Meio Ambiente do RN; João Pessoa: Secretaria de Meio Ambiente do Estado da Paraíba, 2007.

RODRIGUES, R. R.; LEITÃO FILHO, H. F.. Matas Ciliares: conservação e recuperação. 2 ed. São Paulo: EDUSP, 2008.

REIS, A.: ROGALSKI, J. M.. Novos Aspectos na Restauração de Áreas Degradadas. Florianópolis: UFSC, 2006.

SILVA, F. G.; SILVA, R. H.; ARAÚJO, R. M.; LUCENA, M. F. A.; SOUSA, J. M.. Levantamento florístico de um trecho de mata ciliar na mesorregião do Sertão Paraibano. Revista bras. Biociências, Porto Alegre, v.13, n.4, p.250-258, 2016.

A CBPC - Companhia Brasileira de Produção Científica (CNPJ: 11.221.422/0001-03) detém os direitos materiais desta publicação. Os direitos referem-se à publicação do trabalho em qualquer parte do mundo, incluindo os direitos às renovações, expansões e disseminações da contribuição, bem como outros direitos subsidiários. Todos os trabalhos publicados eletronicamente poderão posteriormente ser publicados em coletâneas impressas sob coordenação da Sustenere Publishing, da Companhia Brasileira de Produção Científica e seus parceiros autorizados. Os (as) autores (as) preservam os direitos autorais, mas não têm permissão para a publicação da contribuição em outro meio, impresso ou digital, em português ou em tradução. 